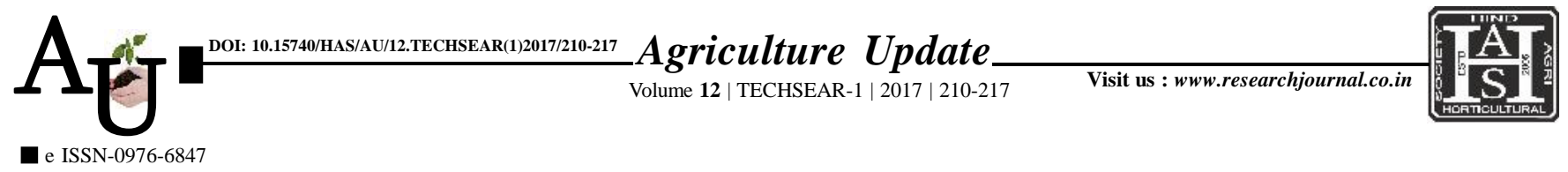

\title{
Research Article: Strengthening of sericulture industry through fortification of mulberry leaves to enhance commercial cocoon characteristics of silkworm
}

N. MALA, FATIMA SADATILLA AND S. HARISH BABU

Article Chronicle:

Received :

11.07.2017;

Accepted :

26.07.2017

KEY WoRds:

Sericulture,

Fortification,

Mulberry leaves,

Silkworm, Cocoon
SUMMARY : Studies on strengthening of Sericulture though fortification of mulberry leaves with aqueous extracts of medicinal plants on larval growth, development and commercial cocoon traits of silkworm, Bombyx mori L. were conducted during 2013-2014. The silkworm ( $\mathrm{PMxCSR}_{2}$ ) reared on mulberry leaves fortified with aqueous extracts of Aloe vera and Tinospora cordifolia at eight different concentrations, Aloe vera at $100 \%$ concentration had effective enhancement of larval weight $(3.37 \mathrm{~g})$, ERR (96.33\%), cocoon weight (2.01g), shell weight (0.375g), pupal weight (1.64g), shell ratio (18.66\%), silk productivity $\left(4.83 \mathrm{cg} \mathrm{day}^{-1}\right)$, filament length $(883.95 \mathrm{~m})$ and denier $(2.41)$ besides reduced larval duration (7.76 days) and disease incidence (3.67\%) when compared to other treatments and control. The plant extracts in higher concentration yielded beneficial effects rather in lesser concentration. This study helps to improve the quality of silkworm nutrition so as to get sustainable cocoon production

How to cite this article : Mala, N., Sadatilla, Fatima and Babu, S. Harish (2017). Strengthening of sericulture industry through fortification of mulberry leaves to enhance commercial cocoon characteristics of silkworm. Agric. Update, 12(TECHSEAR-1) : 210-217; DOI: 10.15740/HAS/AU/12.TECHSEAR(1)2017/210-217.
Author for correspondence :

\section{N. MALA}

Department of Sericulture, University of Agricultural Sciences, G.K.V.K., BENGALURU (KARNATAKA) INDIA

See end of the article for authors' affiliations 